\title{
A GRAMATICALIZAÇÃO DE CAPAZ EM PORTUGUÊS BRASILEIRO E EM ESPANHOL
}

\author{
THE GRAMATICALIZATION OF CAPAZ IN \\ BRAZILIAN PORTUGUESE AND SPANISH
}

\author{
Patrícia de Araújo Rodrigues ${ }^{1}$ \\ Marcus Vinicius Lunguinho ${ }^{2}$
}

\begin{abstract}
Resumo: Este artigo discute diferentes estágios de gramaticalização da expressão capaz em português brasileiro e em espanhol. Nessas línguas, capaz pode funcionar como um adjetivo predicativo (com significado de 'apto') e pode corresponder a um modal de habilidade: João é capaz de dançar tango / Juan es capaz de bailar tango. Essas mesmas sentenças veiculam também uma leitura epistêmica: É provável que João dance tango. O português brasileiro e o espanhol americano, mas não o espanhol peninsular, apresentam ainda um uso epistêmico particular de capaz, com um complemento finito: (É) capaz que ninguém vá na sua casa / (Es) capaz que nadie vaya a su casa. Além desses usos, o português brasileiro apresenta um uso em que capaz funciona como um marcador discursivo, indicando surpresa e/ou ponto de vista negativo do falante: Capaz que a Maria casou!. Propomos que, a cada reanálise, capaz ocupa uma posição mais alta na estrutura oracional, estabelecendo um percurso de gramaticalização característico: perda do sentido etimológico > desenvolvimento do sentido epistêmico (estruturas bioracionais e mono-oracionais) > aquisição de função discursiva (estrutura mono-oracional).
\end{abstract}

Palavras-chave: capaz; modalidade; gramaticalização.

\begin{abstract}
This article discusses different stages of grammaticalization of the expression capaz in Brazilian Portuguese and Spanish. In these languages, capaz can function as a predicative adjective (meaning 'able' / 'capable') and correspond to an abilitative modal: João é capaz de dançar tango / Juan es capaz de bailar tango. These sentences also convey an epistemic meaning: João is likely to dance tango. Brazilian Portuguese and American Spanish, but not European Spanish, still have a particular epistemic use of capaz, with a finite complement: (É) capaz que ninguém vá na sua casa / (Es) capaz que nadie vaya a su casa. Besides, there are constructions in Brazilian Portuguese where capaz functions as a discourse marker, indicating surprise/negative point of view of the speaker: Capaz que a Maria casou!. We propose that, at each reanalysis, capaz occupies a higher position in the clausal structure, establishing a characteristic grammaticalization path: loss of etymological sense > development of epistemic sense (bi-clausal structures) $>$ acquisition of discursive function (mono-clausal structure).
\end{abstract}

Keywords: capaz; modality; grammaticalization.

\footnotetext{
${ }^{1}$ Universidade Federal do Paraná (UFPR), Curitiba, PR, Brasil. patricia.rodrigues@ufpr.br. Orcid: https://orcid.org/0000-0002-3534-284X.

${ }^{2}$ Universidade de Brasília (UnB), Brasília, DF, Brasil. Endereço eletrônico: marcusvsl@unb.br.

Orcid: https://orcid.org/0000-0002-2871-0739.
} 


\section{INTRODUÇÃO}

Neste trabalho, discutimos a expressão capaz em português brasileiro e em espanhol em diferentes contextos de utilização, que caracterizamos como diferentes estágios de gramaticalização dessa expressão. Esses estágios podem ser identificados com as leituras modal de habilidade (1), modal epistêmico (2) e marcador discursivo (3). ${ }^{3}$

(1) a. O mergulhador é capaz de ficar muito tempo embaixo da água.

b. Un líder es capaz de ver las cosas desde el punto de vista de los demás. (CREA)

(2) a. Sandra é capaz de denunciar sua vizinha qualquer dia desses.

b. Sandra es capaz de denunciar a su vecina cualquier día. (CASTROVIEJO; OLTRAMASSUET, 2018, p. 1)

(3) a. Capaz que a Maria casou!

b. ¡Qué capaz! Nunca haré lo que usted me propone. (RODRÍGUEZ ESPIÑEIRA, 2018, p. 133) ${ }^{4}$

Nossa proposta é que esses diversos tipos de capaz estão relacionados e podem ser reconhecidos a partir de critérios propostos na literatura para descrever o processo de gramaticalização. De modo geral, o fenômeno da gramaticalização envolve um processo de mudança linguística por meio do qual itens lexicais assumem um estatuto gramatical, e itens gramaticais, um estatuto ainda mais gramatical (cf. ROBERTS; ROUSSOU, 2003; VAN GELDEREN, 2004; ROBERTS, 2007, 2014, em uma perspectiva gerativista, e HOPPER; TRAUGOTT, 2003; HEINE; NARROG, 2012; LEHMANN, 2015, em uma perspectiva funcionalista). Heine e Narrog (2012), por exemplo, propõem um conjunto de quatro parâmetros a serem utilizados na identificação e descrição de instâncias de gramaticalização: extensão, dessemantização, descategorização e erosão. O parâmetro da extensão diz respeito ao surgimento de novos significados a partir da extensão da expressão linguística a novos contextos; o parâmetro da dessemantização, ou semantic bleaching, diz respeito a perdas no conteúdo semântico da expressão original; o parâmetro da descategorização diz respeito a perdas de propriedades morfossintáticas características das formas analisadas; e o parâmetro da erosão diz respeito a perdas de substância fonética.

Com base nesses parâmetros, apresentamos uma discussão sobre a gramaticalização de capaz a partir da análise dos diferentes usos dessa expressão no português brasileiro e no espanhol. Ressaltamos, contudo, que, embora essa descrição seja feita em termos de generalizações sincrônicas, ela se baseia, por um lado, em mudanças gramaticais regulares já observadas diacronicamente em estudos sobre modais e, por outro lado, em estudos diacrônicos sobre a gramaticalização de capaz para o espanhol, como Grández Ávila (2010) e Rodríguez Espiñeira (2018) - essa última autora também discute, comparativamente, o processo de gramaticalização de capaz no português. Nossa proposta, seguindo Roberts e Roussou (2003), para quem o percurso de gramaticalização de um dado morfema ocorre sempre a partir de uma posição mais baixa

\footnotetext{
${ }^{3}$ Em relação aos exemplos apresentados neste trabalho, é importante mencionar o seguinte: os exemplos referentes ao português brasileiro são de autoria dos autores ou resultam de coleta feita na literatura ou na internet; já os exemplos referentes ao espanhol são provenientes de coleta feita na literatura ou em corpora. Os exemplos que são de nossa autoria aparecem sem nenhuma indicação de fonte, ao passo que os exemplos que não são de nossa autoria aparecem com a referência da fonte de onde eles foram colhidos.

${ }^{4}$ Uso restrito a certas variedades andinas e centro americanas.
} 
para uma posição mais alta na estrutura hierárquica das categorias funcionais, é que, a cada reanálise, capaz ocupa uma posição mais alta na estrutura oracional, estabelecendo um percurso de gramaticalização característico: perda do sentido etimológico > desenvolvimento do sentido epistêmico (estruturas bioracionais e mono-oracionais) > aquisição de função discursiva (estrutura mono-oracional).

$\mathrm{O}$ artigo está organizado como segue. Na seção 2, apresentamos os usos de capaz em português brasileiro e em espanhol. As seções 3, 4 e 5 detalham esses usos: o uso de capaz como expressão de habilidades, o uso de capaz como modal epistêmico e o uso de capaz como um elemento discursivo, respectivamente. A seção 6 traz elementos importantes a serem considerados em uma proposta de análise de capaz, e a seção 7, por fim, traz as considerações finais do artigo.

\section{OS USOS DE CAPAZ EM PORTUGUESS BRASILEIRO E EM ESPANHOL}

Nesta seção, apresentaremos brevemente os usos de capaz em português brasileiro e em espanhol. Antes de passar a esses usos propriamente ditos, tratemos um pouco da diacronia da palavra capaz.

Em sua origem, capaz deriva do latim capax, -cis, que significava 'que pode conter, que pode apreender ou que pode compreender'. Dessa palavra, derivaram muitas formas em línguas românicas: capaz em português e em espanhol, capable em francês, capace em italiano, capaç em catalão. Trazendo a discussão para o campo do português e do espanhol, vemos que a forma fonética da palavra em latim não se altera de modo significativo e acaba produzindo um resultado idêntico em ambas as línguas: capaz. Um ponto importante a destacar é que a convergência formal entre as duas línguas não implica convergência em relação aos usos de capaz. Essa palavra tem, ao todo, três usos, sendo dois deles comuns ao português brasileiro e ao espanhol e um deles mais restrito ao português brasileiro, com uma variante no espanhol andino, aparentemente. Apresentamos esses usos nas seções seguintes.

\subsection{Usos de capaz comuns ao português brasileiro e ao espanhol}

Como dissemos, a palavra capaz apresenta dois usos que são encontrados tanto em português brasileiro como em espanhol. O primeiro uso de capaz é como um adjetivo, uso esse ilustrado nos exemplos em (1), repetidos como (4), por conveniência:

(4) a. O mergulhador é capaz de ficar muito tempo embaixo da água.

b. Un líder es capaz de ver las cosas desde el punto de vista de los demás. (CREA)

Nos exemplos acima, o adjetivo capaz denota uma capacidade ou uma habilidade do nominal ao qual está associado. A expressão de capacidades, disposições e habilidades diz respeito a um dos tipos de modalidade conhecido como modalidade habilitativa ou dinâmica (cf. VON WRIGHT, 1951; KENNY, 1976; PALMER, 2001; PORTNER 2009). A semântica do adjetivo capaz nos exemplos acima faz dele um meio de expressão desse tipo (ou desse sabor) modal. Sendo assim, vamos nos referir a esse uso de capaz como capaz habilitativo.

O segundo uso de capaz presente em ambas as línguas é ilustrado em (2), repetido como (5): 
(5) a. Sandra é capaz de denunciar sua vizinha qualquer dia desses.

b. Sandra es capaz de denunciar a su vecina cualquier día. (CASTROVIEJO; OLTRAMASSUET, 2018, p. 1)

Os exemplos em (5) se assemelham aos exemplos em (4), uma vez que, superficialmente, eles têm a seguinte estrutura: [sujeito - cópula - capaz - de - $\mathrm{V}_{\text {INFINITIvo]. }}$ No entanto, os exemplos em (5) apresentam uma dimensão interpretativa que não há em (4): eles são usados para expressar a possibilidade de que aconteça o que se descreve no infinitivo, tomando como base o conhecimento do falante e as evidências de que ele dispõe. No caso de (5), dependendo do que o falante sabe sobre o mundo e sobre Sandra, é possível que ela denuncie sua vizinha. A expressão de necessidades e possibilidades com base no conhecimento do falante ou com as evidências disponíveis é um outro tipo de modalidade, denominado modalidade epistêmica (cf. KRATZER 1981, 1991, 2012; BYBEE; PERKINS; PAGLIUCA, 1994; PALMER, 2001; PORTNER, 2009). Por veicular modalidade epistêmica em (5), vamos nos referir a esse uso de capaz como capaz epistêmico.

Além de poder vir acompanhado de um complemento infinitivo, capaz epistêmico ainda pode aparecer em outros contextos:

(6) a. (É) capaz que ninguém vá até a sua casa.

b. (Es) capaz que nadie vaya a su casa. (GRÁNDEZ ÁVILA, 2010, p. 32)

(7) a. Nas finais com esse time ridículo, e pela incompetência dos demais envolvidos no torneio, capaz sermos campeões ${ }^{5}$.

b. Capaz le pasó algo y no tiene modo de comunicarse con nosotros. (DIEA apud NEGRONI; SPINOLA, 2013, p. 56)

Em (6), capaz é seguido de complementos finitos introduzidos pelo complementizador que e, em (7), capaz aparece em construções aparentemente semelhantes em português brasileiro e em espanhol, sem a presença de complementizador.

\subsection{Uso de capaz presente apenas em português brasileiro} abaixo:

O terceiro uso de capaz parece ser restrito ao português brasileiro e é ilustrado

(8) a. Capaz que a Maria casou! (= 3a)

b. A: Você sabia que a Maria casou?

B: Capaz! ${ }^{6}$

\footnotetext{
${ }^{5}$ Dado coletado em: https://adrenaline.com.br/forum/threads/futebol-contratacoes-opinioes-divergencias10.566544/page-1314. Acesso em: 18 nov. 2020.

${ }^{6}$ Como nos foi apontado por um parecerista anônimo, em (8b), em seu uso como negação enfática, capaz pode estar negando o conhecimento do falante acerca do casamento da Maria ou pode estar negando o casamento da Maria:

(i) A: Você sabia que a Maria casou?

B: Capaz!

a. Capaz que eu sabia que a Maria casou!

b. Capaz que a Maria casou!

Interpretamos essa dupla possibilidade de negação associada a capaz como produto de dois fatores, quais sejam, o fato de capaz aparecer sozinho na resposta de B e o fato de a pergunta de A ser composta de duas
} 
Os exemplos em (8) são usados para expressar o ponto de vista do falante em relação ao que é expresso, mostrando surpresa em relação ao fato de a Maria ter se casado ou incredulidade ou negação enfática em relação a esse fato. No uso para marcar surpresa, capaz pode ser parafraseado como não acredito, tá brincando, como vemos em (9a) e $(9 b)$, que tomam como base o exemplo (8a) ${ }^{7}$ :

(9) Capaz que a Maria casou!

a. Não acredito que a Maria casou! Logo ela que disse que não queria casar.

b. Tá brincando que a Maria casou! Nunca que eu ia imaginar a Maria casando.

Já quando é usado para marcar incredulidade ou negação enfática do falante em relação a algo que lhe é dito, capaz pode ser parafraseado como de jeito nenhum, conforme se vê no exemplo a seguir, que também parte de (8a):

(10) Capaz que a Maria casou!

a. De jeito nenhum que ela casou! Isso é impossível!

b. A Maria não casou de jeito nenhum! Isso é impossível!

Rodríguez Espiñeira (2018) menciona que, nas áreas centro americanas e andinas, a negação enfática pode ser veiculada pela locução exclamativa qué capaz, como se vê em (11). Essa é a única referência que encontramos na literatura com relação a esse uso de capaz.

(11) ¡Qué capaz! Nunca haré lo que usted me propone. (SANDOVAL 1941-1942: II, 301, Guatemala apud RODRÍGUEZ ESPIÑEIRA, 2018, p. 133) (=3b)

Como esse uso de capaz que acabamos de descrever é fortemente amparado em um ponto do visa do falante, uma entidade do discurso, vamos denominá-lo de capaz discursivo. ${ }^{8}$ Nas seções seguintes, detalharemos cada um dos empregos de capaz.

\section{CAPAZ HABILITATIVO}

Como vimos na seção anterior, o adjetivo capaz pode ser usado para denotar capacidades e habilidades do nominal ao qual está associado. Na literatura sobre modalidade, a expressão de capacidades e habilidades diz respeito a um dos tipos de modalidade reconhecidos: a modalidade habilitativa (ou dinâmica, ou circunstancial). A

orações combinadas por subordinação - cada uma com seu núcleo predicador. Sendo assim, quando capaz é usado sozinho na resposta de B, ele pode ter escopo sobre o predicador saber da oração matriz ou sobre o predicador casar da oração encaixada. No primeiro caso, a negação de capaz incide sobre o conhecimento do falante sobre o casamento da Maria e, no segundo caso, a negação incide sobre o casamento da Maria propriamente. Essas possibilidades de escopo de capaz na sua leitura como marcador de incredulidade / negação enfática não haviam sido abordadas em Rodrigues e Lunguinho (2019) e são importantes, pois podem apontar para uma separação entre os sentidos de surpresa e de incredulidade / negação enfática de capaz, uma vez que essas possibilidades de escopo não parecem estar possíveis quando capaz veicula surpresa do falante. Essa é uma questão cuja investigação deixamos em aberto para pesquisas futuras.

7 Agradecemos a um parecerista anônimo, por compartilhar conosco paráfrases para cada um desses sentidos, as quais aparecem em (9) e em (10). Em relação a paráfrases para capaz, ver Bassi e Görski (2014).

${ }^{8}$ Uso esse que foi denominado por Rodrigues e Lunguinho (2019) de capaz mirativo. 
semântica do adjetivo capaz nesses casos faz dele um meio de expressão desse tipo (ou desse sabor) modal.

Primeiramente, capaz habilitativo pode ser usado tanto em posição predicativa, em (12), como em posição de adjunto / atributiva, em (13). Nestes exemplos, capaz aparece sem complemento:

(12) a. Nossos alunos são bastante capazes.

b. Es estudiante de Derecho (primer año) e intelectualmente es muy capaz. (CREA)

(13) a. Nossos alunos mais capazes foram selecionados para essa competição.

b. Sabe rodearse de gente capaz. (CREA)

Do ponto de vista de sua complementação, capaz habilitativo pode se combinar com um complemento oracional infinitivo:

(14) a. Um atleta amador é capaz [de correr uma maratona].

b. El buen arquitecto es capaz [de diseñar muebles] [...]. (CREA)

(15) a. Esse material é capaz [de impedir o som].

b. La vitamina E es capaz [de mejorar la inmunidad en la tercera edad]. (CREA)

(16) a. A emancipação torna o candidato plenamente capaz [para praticar todos os atos da vida civil $[\ldots]^{9}$

b. La infraestructura deportiva, cultural y asociativa no parece capaz [para ofrecer servicios a aquellos alumnos con alguna aspiración más allá de la televisiva]. (CREA)

Em (14) e (15), os complementos infinitivos são introduzidos pela preposição de, enquanto em (16), eles são introduzidos pela preposição para. A preposição para, no entanto, não é frequente nesses contextos, sendo o uso da preposição de largamente preponderante.

A expressão capaz, no sentido habilitativo, também se combina com complementos de natureza nominal, introduzidos pela preposição $d e$ :

(17) a. Essa pessoa é capaz [das mais belas demonstrações de carinho].

b. Todavía debe quedar bastante vida en mí porque soy capaz [de una explosión semejante], casi vergonzosa, como en mis mejores tiempos. (CREA)

No caso da complementação nominal de capaz, há uma diferença a ser observada entre o português brasileiro e o espanhol: ao contrário do português brasileiro, o espanhol aceita complementos nominais introduzidos pela preposição para, como em (18a). Nesses casos, no entanto, conforme o Diccionario Panhispánico de Dudas (DPD), capaz tem o sentido de "que tem espaço suficiente para conter algo". ${ }^{10} \mathrm{O}$ referido dicionário menciona, ainda, que, sem complemento, capaz também pode significar "espaçoso, que pode conter muitas coisas", como em (18b).

\footnotetext{
${ }^{9}$ Dado coletado em: https://www.tabeliaodebarueri.com.br/emancipacao-torna-jovem-capaz-para-exercercargo-publico/. Acesso em: 21 nov. 2020.

${ }^{10}$ Conforme Rodriguez Espiñeira (2018), no uso atual do espanhol, é a preposição para, e não de, que prevalece no caso de um complemento nominal com o sentido de "que pode conter".
} 
(18) a. Una bañera a ras del suelo, capaz para dos o tres personas. (DPD)

b. Los cajones eran bastante capaces. (DPD)

Ainda é possível observar que, nos exemplos em (15), capaz se aplica a entidades inanimadas. Esse tipo de predicação não é possível quando capaz aparece sem complemento:

(19) a. Esta TV é capaz * (de reproduzir conteúdo em 4k).

b. El nuevo estádio, bajo techo, seria capaz *(de albergar hasta 120.000 espectadores). (CREA)

A natureza adjetiva de capaz habilitativo fica evidente em suas propriedades morfológicas: capaz se flexiona em número (20), aceita modificação de grau (21) e pode ser tomado como base em uma derivação (22):

(20) a. O presidente ainda dispõe de instrumentos capazes de reverter o quadro de derrotas.

b. También existen formas de linfocitos capaces de destruir directamente a la célula infectada. (CREA)

(21) a. Falta muito para desenvolvermos robôs que sejam tão capazes quanto os seres humanos

b. Debe ser suficiente con la existencia de la OCI, dirigida por una persona tan capaz como el actual director. (CREA)

(22) a. Existem várias tarefas que os robôs são incapazes de executar.

b. Es un buen tipo, incapaz de hacerle daño a nadie. (CREA)

Como se vê, capaz se flexiona a depender dos traços de número do nome ao qual está associado - ele aparece no singular nos exemplos (14) porque os substantivos com os quais se relaciona têm traço de singular, ao passo que ele aparece no plural em (20) por conta do traço de plural dos substantivos com os quais se relaciona. $\mathrm{O}$ adjetivo capaz também permite modificadores de grau como tão ... quanto no exemplo (21a) e bastante no exemplo (12a) no caso do português; e tan ... como no exemplo (21b) e muy no exemplo (12b) no caso de espanhol. Finalmente, capaz pode sofrer a afixação do prefixo in-, formando a palavra incapaz, que recupera a semântica da base, como se vê em (22).

Em síntese, a discussão acima mostra que, tanto em português brasileiro quanto em espanhol, capaz apresenta as propriedades de um adjetivo pleno, com sentido de habilidade / capacidade. Nas duas línguas, capaz pode aparecer sem complementos ou com complementos infinitivos ou nominais. Uma distinção pode ser observada, no entanto: em espanhol, ao contrário do português brasileiro, capaz aceita complementos nominais introduzidos por para. Nesse caso, há clara manutenção do sentido original de capacidade uma vez que capaz significa, nessas construções, potencial para armazenamento, sentido esse que também pode ser verificado em usos de capaz sem complemento. 


\section{CAPAZ EPISTÊMICO}

Na leitura epistêmica, capaz expressa a possibilidade de que aconteça o que se descreve no seu complemento, tomando como base o conhecimento de mundo do falante e as evidências de que ele dispõe. Os exemplos abaixo ilustram esse uso modal. ${ }^{11}$

(23) a. Sandra é capaz de denunciar sua vizinha qualquer dia desses.

b. Sandra es capaz de denunciar a su vecina cualquier día. (CASTROVIEJO; OLTRA-MASSUET, 2018, p. 1)

(24) a. (É) capaz de Sandra denunciar sua vizinha qualquer dia desses.

b. ${ }^{*}$ Es capaz de Sandra denunciar a su vecina cualquier día. ${ }^{12}$

c. "Capaz de Sandra denunciar a su vecina cualquier día.

(25) a. (É) capaz que ninguém vá até a sua casa.

b. (Es) capaz que nadie vaya a su casa. (GRÁNDEZ ÁVILA, 2010, p. 32)

(26) a. Nas finais com esse time ridículo, e pela incompetência dos demais envolvidos no torneio, capaz sermos campeões.

b. Capaz le pasó algo y no tiene modo de comunicarse con nosotros. (DIEA apud NEGRONI; SPINOLA, 2013, p. 56)

Nas sentenças em (23), aceitáveis tanto em português brasileiro como em espanhol, a cópula ser apresenta um sujeito lexical. Os exemplos em (24) mostram uma diferença entre o português e o espanhol: em português, mas não em espanhol, a cópula pode ser omitida e o sujeito lexical aparece na posição de sujeito da oração infinitiva. Em (25), com exemplos aceitáveis nas duas línguas, a cópula é opcional e capaz epistêmico aparece com complemento finito introduzido pelo complementizador que. Em (26), segue-se a capaz uma oração sem a presença do complementizador. As seções que seguem discutem essas diferentes estruturas em que capaz epistêmico aparece.

\subsection{Estrutura 1: sujeito - ser $-c a p a z-\left[d e-V_{\mathrm{INF}}\right]$}

É necessário observar, em primeiro lugar, que as construções nas quais a cópula ser apresenta um sujeito lexical e o adjetivo capaz seleciona um complemento infinitivo podem ser ambíguas entre uma leitura habilitativa e uma leitura epistêmica, como em (27) (cf. CASTROVIEJO; OLTRA-MASSUET, 2018):

(27) a. Hobbes é capaz de traduzir as obras completas de Homero.

b. Hobbes es capaz de traducir las obras completas de Homero. (CASTROVIEJO; OLTRA-MASSUET, 2018, p. 3)

Na leitura habilitativa de (27), capaz expressa a disposição de Hobbes para traduzir as obras completas de Homero. Em outras palavras, dada sua capacidade intelectual, Hobbes tem a habilidade, a aptidão, para traduzir as obras de Homero. Na

${ }^{11}$ Os exemplos (23), (25) e (26) repetem os exemplos (5), (6) e (7), respectivamente.

${ }^{12}$ Em espanhol, o sujeito lexical não pode aparecer na posição de sujeito da oração infinitiva nem nos casos de inversão sujeito-verbo:

(i) a. "Es capaz de denunciar Sandra a su vecina cualquier día.

b. "Capaz de denunciar Sandra a su vecina cualquier día. 
leitura epistêmica, capaz expressa a possibilidade de que Hobbes, em algum momento, venha a traduzir tais obras. De acordo com Castroviejo e Oltra-Massuet (2018), a possibilidade dessas duas leituras é uma característica das construções com aspecto imperfectivo. As autoras mostram também que a leitura epistêmica desaparece quando a sentença apresenta aspecto perfectivo (28), mas essa leitura é a única possível quando a prejacente está no escopo de um operador aspectual (29):

(28) a. Hobbes foi capaz de traduzir as obras completas de Homero.

b. Hobbes fue capaz de traducir las obras completas de Homero. (CASTROVIEJO; OLTRA-MASSUET, 2018, p. 3)

(29) a. Este filósofo é capaz de ter traduzido / estar traduzindo as obras completas de Homero.

b. Este filósofo es capaz de haber traducido / estar traduciendo las obras completas de Homero. (CASTROVIEJO; OLTRA-MASSUET, 2018, p. 3)

Para Castroviejo e Oltra-Massuet, contudo, a leitura que estamos chamando de epistêmica não seria uma leitura "epistêmica pura", mas indicaria uma possibilidade acidental, veiculando habilidades dependentes de ação (action-dependent abilities), isto é, trata-se de uma leitura em que a expressão ser capaz continuaria expressando uma modalidade pessoal, pois o conhecimento da informação para avaliação da prejacente é necessariamente relativo ao agente do evento, o que não seria esperado no caso de uma interpretação epistêmica pura. Ou seja, essa leitura envolve circunstâncias internas ao sujeito, mas, ao contrário da leitura habilitativa, ele não tem controle sobre o evento. Resumidamente: ser capaz selecionaria uma base modal circunstancial, a qual inclui proposições que descrevem circunstâncias internas do sujeito; a leitura habilitativa pura e a leitura de possibilidade acidental vão emergir dependendo da fonte de ordenação. ${ }^{13}$

Para ilustrar a distinção entre leitura epistêmica e leitura acidental, as autoras discutem os exemplos em (30), que diferem na forma da cópula, mas que, em princípio, veiculam o mesmo significado modal. Em (30a), capaz não pode ser interpretado como a expressão de uma habilidade, mas também não poderia ser interpretado como modal epistêmico, pois não se refere a uma conjectura que o falante faz sobre o passado nem a uma conjectura passada; capaz expressaria a imprevisibilidade do fato de a avó ganhar na loteria. Dessa forma, Castroviejo e Oltra-Massuet consideram que (30b) também não veicula leitura epistêmica, mas sim acidental.

(30) a. De jovem, tu abuela era capaz de ganar la loteria y volver a casa con las manos llenas de dinero.

b. Tu abuela es capaz de ganar la loteria. (CASTROVIEJO; OLTRA-MASSUET, 2018, p. 5)

A partir dessa análise, propomos que as diferenças de leitura identificadas em (27) dizem respeito a um passo no percurso de gramaticalização de capaz, que, a partir da leitura habilitativa, adquire a leitura acidental, ainda que essas leituras estejam associadas com a estrutura sintática aparente [X ser capaz de $\mathrm{V}_{\mathrm{INF}}$ ]. Com essa extensão do sentido, há a dessemantização de capaz, que perde o significado de apto / hábil. Capaz também se

\footnotetext{
${ }^{13}$ Para uma descrição de capaz em português brasileiro no quadro da semântica e da pragmática formais, ver Teixeira, Gritti e Koslinski (2019). Nesse trabalho, as autoras propõem uma análise de capaz como modal de possibilidade com quatro tipos de leitura: possibilidade físico-intelectual, possibilidade doxástica, possibilidade epistêmica e possibilidade epistêmico-tácita.
} 
descategoriza, perdendo a capacidade de servir de base para derivações, (31); além disso, a cópula só aceita formas imperfectivas (32).

(31) a. Hobbes é incapaz de traduzir as obras completas de Homero.

(' habilidade / ${ }^{*}$ acidental)

b. Hobbes es incapaz de traducir las obras completas de Homero.

( ${ }^{\checkmark}$ habilidade $/{ }^{*}$ acidental)

(32) a. Hobbes foi capaz de traduzir as obras completas de Homero.

( ${ }^{\checkmark}$ habilidade $/{ }^{*}$ acidental)

b. Hobbes fue capaz de traducir las obras completas de Homero.

( ${ }^{\vee}$ habilidade $/{ }^{*}$ acidental)

Ainda com relação à estrutura [sujeito - é - capaz - complemento infinitivo], vejamos o exemplo (33):

(33) Un experimento capaz de ser repetido en diferentes circunstancias (DI TULLIO; KORNFELD, 2013, p. 88)

Di Tullio e Kornfeld (2013) discutem esse exemplo e, para elas, a estrutura na qual capaz recebe uma interpretação epistêmica (própria de uma oração impessoal) seguido de verbo na forma passiva é um caso particular, marginal.

Com base em (33), é possível encontrar exemplos como (34):

(34) a. A alegria é capaz de ser expressada de diversas maneiras. ${ }^{14}$

b. El contenido es capaz de ser reproducido infinidad de veces. ${ }^{15}$

Em síntese, com relação à estrutura [sujeito - ser - capaz - [ de - VINF ]], português e espanhol se comportam de forma semelhante.

\subsection{Estrutura 2: (ser) - capaz - [ de - sujeito - V INF ]}

Um outro estágio no processo de gramaticalização de capaz em português brasileiro se consumaria com a presença de um sujeito pleno no domínio infinitivo, como em (24a), repetido em (35) por conveniência:

(35) (É) capaz de Sandra denunciar sua vizinha qualquer dia desses.

No exemplo acima, o verbo ser torna-se impessoal e se fixa na terceira pessoa do singular, podendo, inclusive, ser dispensado. A leitura obtida nesse caso passa de acidental a epistêmica. Rodrigues e Lunguinho (2019) afirmam que, nos casos da leitura habilitativa em português, como em (27), capaz seleciona dois argumentos, um DP e uma oração [de + infinitivo], enquanto capaz epistêmico selecionaria apenas uma oração infinitiva. Essa consolidação do valor epistêmico de capaz em português brasileiro aparece também em exemplos com predicados impessoais, como verbos meteorológicos (36a) ou existenciais (36b), e com expressões idiomáticas (36c):

\footnotetext{
${ }^{14}$ Dado coletado em: https://br.pinterest.com/pin/296533956715227834/. Acesso em: 02 dez. 2020.

15 Dado coletado em: https://es.linkedin.com/pulse/5-motivos-por-los-que-deber\%C3\%ADas-considerardar-cursos-online-acosta. Acesso em: 02 ago. 2021.
} 
(36) a. (É) capaz de chover durante toda a semana.

b. (É) capaz de ter gente que nunca ouviu falar do Pelé.

c. (É) capaz do bicho pegar / da casa cair / da cobra fumar.

Com relação ao espanhol, a configuração sintática com o sujeito pleno no domínio infinitivo não é permitida $(37 \mathrm{a}-\mathrm{b})^{16}$. No entanto, é possível encontrar exemplos do espanhol com predicados meteorológicos, como em (37c-d).

(37) a. *Es capaz de Sandra denunciar a su vecina cualquier día. $(=24 b)^{17}$

b. *Capaz de Sandra denunciar a su vecina cualquier día. $(=24 \mathrm{c})$

c. ¡El tiempo está tan loco que es capaz de nevar en primavera! (RODRÍGUEZ ESPIÑEIRA, 2018, p. 136)

d. Capaz de llover de novo. (RODRÍGUEZ ESPIÑEIRA, 2018, p. 169)

Rodríguez Espiñeira (2018) afirma, porém, que esses tipos de exemplos são dialetais, e Castroviejo e Oltra-Massuet (2018) consideram que eles têm aceitação divergente por parte dos falantes. Já com relação aos usos com predicados existenciais, Rodríguez Espiñeira afirma não ter encontrado registros escritos.

\subsection{Estrutura 3: capaz - [ que - oração ]}

Mais um estágio de gramaticalização de capaz epistêmico pode ser visto nos exemplos em (25), repetidos em (38), em que capaz aparece com complementos finitos introduzidos pelo complementizador que, seguido do subjuntivo.

(38) a. (É) capaz que ninguém vá até a sua casa.

b. Se ele soubesse a verdade, (era) capaz que não aceitasse o empréstimo.

c. (Es) capaz que nadie vaya a su casa. (GRÁNDEZ ÁVILA, 2010, p. 32)

d. Si no lo hacía, era capaz que la vieja me echara de la casa. (CREA - Guatemala)

Em ambas as línguas, é possível tanto a construção é / es / era - capaz-que como a construção capaz - que, com queda da cópula. Todavia, segundo vários autores (cf. HERNANZ, 1999; GRÁNDEZ ÁVILA, 2010; ALEZA IZQUIERDO, 2010; DI TULLIO; KORNFELD, 2013; RODRIGUEZ ESPIÑEIRA, 2018), essa construção é uma variante do espanhol americano, não sendo frequente no espanhol peninsular, tendo seu uso restrito, segundo Rodriguez Espiñeira (2014), a variedades dialetais e populares. Grández Ávila (2010) afirma que essa construção pode ser encontrada em textos espanhóis dos séculos XVIII e XIX, o que indicaria que, além de ter ocorrido na Espanha, esse uso pode ter sido a fonte do uso nas Américas. O Diccionario Panhispánico de Dudas cita a expressão (es) capaz que como pertencente à fala coloquial de muitos países americanos.

Nos casos em que a cópula está presente, o verbo ser apresenta forma fixa na terceira pessoa do singular, e frequentemente aparece no presente. A possibilidade da

\footnotetext{
${ }^{16}$ Os casos em que um sujeito pleno aparece em um domínio infinitivo parecem resultar, de acordo com Hernanz (1999), de condições bastante particulares, que levam ao relaxamento das restrições correferenciais impostas pela oração matriz à oração subordinada no que se refere à interpretação do sujeito da oração subordinada infinitiva. No caso do exemplo (ia) abaixo, a infinitiva na posição de sujeito reuniria tais condições:

(i) a. Interrogar el fiscal al testigo no era tarea fácil.

b. *Interrogar el fiscal al testigo no me resultó tarea fácil.

${ }^{17}$ A esse respeito, conferir nota 12.
} 
queda da cópula, de acordo com Rodriguez Espiñeira (2018), aponta para a criação de uma forma adverbial capaz que, com o significado de talvez. Segundo a autora, a forma capaz que é posterior à forma é capaz que em espanhol e aparece em contextos próprios de advérbios de dúvida, modalizando, por exemplo, uma oração condicional (39a) ou um advérbio que especifica a polaridade de um conteúdo proposicional (39b).

(39) a. Capaz que si le pido a El Ulalume una fotocopia del oficio, se queda con la copia y me da el original.

b. Claro que no, dirá Lily. - Capaz que sí, dirá Sandro, capaz que nos haría bien a todos. (RODRIGUEZ ESPIÑEIRA, 2018, p. 131)

Uma evidência, para Rodriguez Espiñeira (2018, p. 132), de que capaz que se comporta como advérbio seria a sua pronúncia como unidade acentual em alguns dialetos (40), o que mostraria que a expressão sofreu um tipo de erosão, um dos parâmetros que ajudam na descrição e na identificação do processo de gramaticalização:

(40) $\left[\mathrm{ka} \cdot \mathrm{pa}^{\mathrm{h}} \cdot \mathrm{ke}\right] /\left[\mathrm{ka} \cdot \mathrm{pa}^{\mathrm{s}} \cdot \mathrm{ke}\right] /\left[\mathrm{ka} \cdot \mathrm{pa}^{\theta} \cdot \mathrm{ke}\right]$

Di Tullio e Kornfeld (2013) também afirmam que capaz que é uma forma mais gramaticalizada do que é capaz que, e que o processo de gramaticalização se completa com a perda da cópula, do subjuntivo no complemento e do contexto condicional que a favorece. As autoras propõem a reanálise em (41):

(41) a. [(Es) capaz [que le dé una bofetada]].

b. [Capaz (que)] [le doy una bofetada]. (DI TULLIO; KORNFELD, 2013, p. 89)

Segundo a reanálise proposta, enquanto (41a) é uma estrutura predicativa bioracional, (41b) é uma estrutura mono-oracional, introduzida por capaz que. A análise de estrutura mono-oracional é proposta igualmente por Cruschina e Remberger (2018) para as construções com capaz que do espanhol e para as construções do italiano com capace che, que os autores denominam de construções- $C$ (do inglês, Complementizer constructions $)^{18}$. Eles descrevem essas construções como estruturas em que "o complementizador é precedido por um elemento funcional que coincide morfologicamente com um adjetivo ou com um advérbio"19 (p. 337 - tradução nossa). Os autores não descartam a possibilidade de se aplicar a análise de estrutura bioracional a casos em que a cópula está ausente, mas especificam que a frequência desses casos é baixa. Eles admitem também essa análise para casos em que a cópula e o subjuntivo estão presentes. No entanto, afirmam que a maioria dos exemplos encontrados em corpora relevantes envolvem a presença do indicativo, o que apontaria em direção da análise da estrutura mono-oracional. Em suma, aparentemente, em espanhol, as construções com capaz que são, em sua maioria, casos de construções- $C$.

Em português brasileiro, tanto as construções com é capaz que quanto aquelas com capaz que podem apresentar o subjuntivo:

\footnotetext{
${ }^{18}$ Cruschina e Remberger (2018) discutem diferentes adjetivos e advérbios presentes nas construções-C, como certo, claro / chiaro, capaz / capace, evidentemente. A respeito dessas construções, ver também Kocher $(2014,2017)$.

${ }^{19}$ No original: "the complementizer is preceded by a functional element that morphologically coincides with an adjective or an adverb".
} 
(42) a. É capaz que ele tenha que andar com proteção da polícia pro resto da vida ${ }^{20}$.

b. Os ventos estão soprando do oeste pra leste, capaz que chova ${ }^{21}$.

Nos dialetos que conservam o uso do subjuntivo, a ocorrência desses dois tipos de construção é bastante frequente. Há falantes que também aceitam sentenças em que capaz. que é seguido de verbo no indicativo (capaz que chove hoje), mas, devido à variação dialetal com relação ao uso do subjuntivo ${ }^{22}$, não há como determinar se o uso do indicativo é próprio dessas construções em particular. Em outras palavras, não há como determinar se esses casos apontam de fato para a gramaticalização da expressão. O que é possível observar quando a construção não apresenta a cópula ${ }^{23}$ é a maior frequência da presença do subjuntivo no complemento. Essa configuração não autoriza, portanto, a sua análise como uma estrutura mono-oracional, dado que o subjuntivo é típico de orações subordinadas, conforme também afirmam Rodrigues e Lunguinho (2019). No entanto, os autores observam que, ao contrário das sentenças em que a cópula está presente, as sentenças sem a cópula aceitam mais dificilmente a modificação adverbial de capaz (43ab). Eles acrescentam que esse contraste de aceitabilidade não aparece no caso de modificação pelo advérbio bem (43c).

(43) a. É muito / realmente / perfeitamente capaz que o João seja aprovado no concurso.

b. ??Muito / realmente / perfeitamente capaz que o João seja aprovado no concurso.

c. É bem capaz / Bem capaz que o João seja aprovado no concurso.

Assim, é possível que essas características - a queda da cópula, a restrição à modificação adverbial e a presença do subjuntivo - indiquem: a) que o processo de gramaticalização em português brasileiro já tenha se iniciado, mas ainda não tenha se completado, ou b) que tenha se completado em alguns dialetos, especificamente aqueles em que essas construções aparecem com o indicativo. Apenas um estudo mais aprofundado poderá confirmar essas hipóteses, investigando, por exemplo, se a expressão capaz que forma uma unidade acentual em português ou se a utilização do modo indicativo é própria do processo de gramaticalização dessa expressão e não apenas indício de variação dialetal.

Em síntese, parece haver uma diferença entre o português brasileiro e o espanhol com relação ao uso da expressão capaz que, no sentido de que, no espanhol, essa expressão estaria totalmente gramaticalizada, ao passo que, em português brasileiro, o processo de gramaticalização estaria em curso.

\subsection{Estrutura 4: capaz - oração}

Por fim, há a possibilidade de uso epistêmico de capaz, ilustrado pelos exemplos em (7), repetidos em (44), aparentemente semelhantes entre si:

\footnotetext{
20 Dado coletado em: https://canaltech.com.br/virais/Justica-pela-web-preso-o-homem-que-chutou-umgato-nos-EUA. Acesso em: 04 dez. 2020.

${ }^{21}$ Dado coletado em: https://ask.fm/BiancaAvanzo/best?page=2. Acesso em: 04 dez. 2020.

${ }^{22}$ Estudos variacionistas mostram que a variação no português brasileiro entre formas indicativas e subjuntivas ocorre em todos os contextos de uso do subjuntivo (e.g. Pimpão e Santos 2018).

${ }^{23}$ Essas observações são informais, realizadas em pesquisas em corpora do português brasileiro e na internet, utilizando o Google.
} 
(44) a. Nas finais com esse time ridículo, e pela incompetência dos demais envolvidos no torneio capaz sermos campeões.

b. Capaz le pasó algo y no tiene modo de comunicarse con nosotros. (DIEA apud NEGRONI; SPINOLA, 2013, p. 56)

Outros exemplos do espanhol podem ser vistos em (45):

(45) a. — ¿Vendrá Juan a la tarde? — Capaz. (DIEA apud NEGRONI; SPINOLA, 2013, p. 56)

b. Capaz nos vemos el lunes en la facu. (DIEA apud NEGRONI; SPINOLA, 2013, p. 56)

c. Si siguen las heladas, capaz perderemos la cosecha. (RODRÍGUEZ ESPIÑEIRA, 2018: 132).

d. Capaz lo tengan que operar. (RODRÍGUEZ ESPIÑEIRA, 2018: 132).

e. Es um departamento muy lindo, capaz / por ahí un pouco chico. (DI TULLIO; KORNFELD, 2013, p. 92)

De acordo com os dados, em espanhol, capaz parece funcionar como um advérbio de dúvida, um marcador de modalidade epistêmica, em contextos em que pode alternar com capaz que ou em contextos de pergunta-resposta (cf. RODRÍGUEZ ESPIÑEIRA, 2018). Di Tullio e Kornfeld (2013) afirmam que capaz também pode ter alcance mais reduzido, aplicando-se, por exemplo, a um nominal, como se vê em (45e).

Há, contudo, uma clara distinção a ser feita entre o português brasileiro e o espanhol nesses casos. Ainda que o português brasileiro possa apresentar usos do tipo de (45a), os outros usos exemplificados em (45) não podem, em princípio, ser reproduzidos nessa língua ${ }^{24}$. O exemplo em (44a) é um caso bastante específico e bem pouco frequente na língua. Ele não seria, pois, comparável aos exemplos do espanhol. Mais frequentes são exemplos como (46), que se caracterizam pela presença da cópula e nos quais a oração infinitiva é claramente sujeito da oração.

(46) a. Você mostrou que é capaz amarmos as pessoas sem conhecer pessoalmente ${ }^{25}$.

b. Olha, é capaz amarmos como uma mãe $[\ldots]^{26}$

c. Seria capaz sabermos quando mais ou menos isso aconteceu? ${ }^{27}$

Esses dados sugerem que, nesses casos específicos, o processo de gramaticalização de capaz epistêmico estaria mais avançado em espanhol do que em português brasileiro.

\footnotetext{
${ }^{24}$ Acerca de construções nas quais capaz aparece seguido por uma oração finita sem complementizador, encontramos apenas um dado em um diálogo de whatsapp. No diálogo, o nome da pessoa mencionada é substituído por B, para preservar sua identidade:

Contexto: A e B estão discutindo a confecção de cartazes, mencionando diversas profissões.

A: B, não fizeram de aposentado?

B: Só recebi essas.

A: Certo. Capaz ainda apareça.

${ }^{25}$ Dado coletado em: https://www.picterio.com/tag/parabenssimonemendes. Acesso em: 07 dez. 2020.

${ }^{26}$ Dado coletado em: https://www.tammycezaretti.com.br/2015/08/. Acesso em: 07 dez. 2020.

27 Dado coletado em: https://br.answers.yahoo.com/question/index?qid=20170804112941AAZua3J. Acesso em: 07 dez. 2020.
} 


\section{CAPAZ DISCURSIVO}

Capaz ainda funciona em português brasileiro e em espanhol como um marcador discursivo, como nos exemplos (8) e (9), repetidos em (47) e (48).

(47) a. Capaz que a Maria casou!

b. A: Você sabia que a Maria casou?

B: Capaz!

(48) ¡Qué capaz! Nunca haré lo que usted me propone. (SANDOVAL 1941-1942: II, 301, Guatemala apud RODRÍGUEZ ESPIÑEIRA, 2018, p. 133)

Em português brasileiro, capaz pode ser acompanhado de um complemento finito no indicativo ou aparecer isoladamente. Em ambos os casos, capaz expressa surpresa, incredulidade, ou o ponto de vista negativo do falante e apresenta uma entoação distinta da entonação do capaz com usos epistêmicos ${ }^{28}$. De acordo com Rodrigues e Lunguinho (2019), essas nuances no sentido de capaz podem ser observadas nos exemplos abaixo, extraídos de Bassi e Görski (2014, p. 605).

(49) Na: Sabia que a minha filha disse que essas cores que você escolheu para fazer os tapetes vão ficar bem bonitas juntas?

Ni: Capaz que ela disse isso! Que legal!

(50) C: Essa carne que você assou hoje ficou dura.

M: Capaz!! Eu fiz com tanto cuidado!

(51) L: Se chover assim não vai ter a Semana Farroupilha.

M: Capaz que não!

(52) F: A gente poderia, neste feriado, ir pescar lá no Guaíba. O que tu acha da minha ideia?

R: Ah tá, capaz que eu vou pescar contigo! Nem falar.

Em (49) e (50), capaz tem o mesmo sentido das expressões Eu não acredito!, $E$ verdade?, É mesmo?. Já em (51) e (52), capaz expressa o ponto de vista contrário do falante a respeito do que foi afirmado pelo seu interlocutor. Rodrigues e Lunguinho (2019, p. 563) afirmam que, muitas vezes, o enunciado com capaz discursivo é ambíguo entre a expressão da surpresa e a da negação: em (50), por exemplo, não se sabe se $M$ só manifesta surpresa com a afirmação de $\mathrm{C}$ ou se manifesta um posicionamento contrário,

\footnotetext{
${ }^{28}$ Destacamos diferenças entonacionais em relação aos usos epistêmicos e discursivos de capaz. Um parecerista anônimo apontou que, em seu dialeto, o capaz que expressa surpresa e incredulidade do falante apresenta uma entonação distinta também da entonação do capaz que é associado à atitude negativa do falante, ou seja, de acordo com o relato desse parecerista, entre os usos discursivos de capaz, há também diferenças entonacionais. Como nosso objetivo neste trabalho é mais voltado a um recorte que privilegia a relação entre a morfossintaxe e a semântica / pragmática dessa expressão, em uma perspectiva comparativa, não faremos um estudo aprofundado das diferentes entonações associadas a cada um dos usos de capaz. Reconhecemos, contudo, que essa diferença constitui uma questão de interface muito importante para o entendimento dos diferentes usos dessa expressão e ela carece de investigação.
} 
discordando de C. Assumimos, conforme Rodrigues e Lunguinho (2019), que não é possível analisar capaz discursivo apenas como uma negação enfática. ${ }^{29}$

Vimos que capaz discursivo e capaz epistêmico diferem na entonação e na forma verbal do seu complemento. Além dessas diferenças, podemos apontar mais duas: capaz discursivo não seleciona complementos infinitivos e não pode aparecer em orações encaixadas (exemplos extraídos de Rodrigues e Lunguinho, 2019, p. 16):

(53) a. "Capaz da Maria viajar de ônibus!

b. ${ }^{\#}$ O João disse / acha que capaz que a Maria viajou de ônibus!

Os exemplos em (53) só apresentam a leitura epistêmica.

O exemplo em (48), do espanhol americano, também veicula um uso discursivo de capaz. Segundo Rodríguez Espiñeira (2018, p. 132), que se apoia na Nueva Gramática de la Lengua Española, a expressão qué capaz se emprega nas áreas centroamericana e andina "como negação enfática, isto é, para rejeitar uma possibilidade levantada, com valor semelhante a de 'absolutamente impossível'” (tradução nossa). ${ }^{30}$ A autora, que desenvolveu um estudo sobre as mudanças sintáticas e semânticas de capaz, esclarece que não encontrou pistas que expliquem o valor negativo desta expressão. Como mencionamos na seção 2, essa foi a única referência encontrada na literatura sobre ocorrências de capaz discursivo em espanhol.

\section{PERSPECTIVAS PARA UMA PROPOSTA DE ANÁLISE}

Considerando a discussão acima, bem como a abordagem de Roberts e Roussou (2003) com relação ao percurso de gramaticalização de um dado morfema, que ocorreria sempre a partir de uma posição mais baixa para uma posição mais alta na estrutura hierárquica das categorias funcionais, propomos que, a cada reanálise, capaz ocupa uma posição mais alta na estrutura oracional, estabelecendo um percurso de gramaticalização característico: perda do sentido etimológico > desenvolvimento do sentido epistêmico (estruturas bioracionais e mono-oracionais) > aquisição de função discursiva (estrutura mono-oracional).

Capaz adjetivo pleno / habilitativo seria núcleo de sua própria projeção adjetival. Quando o complemento selecionado é uma oração, tem-se uma estrutura bi-oracional. A partir da gramaticalização dessa expressão, resultariam as outras formas de capaz. Com relação a capaz epistêmico, propomos estágios de gramaticalização distintos, com a consequente ocorrência em posições distintas na estrutura da sentença. Em concordância com Castroviejo e Oltra-Massuet (2018), ser capaz com leitura acidental se encontra em uma posição mais alta na estrutura que ser capaz habilitativo, porém mais baixa que um modal epistêmico puro. Como vimos na seção 4, sobre a descrição de capaz epistêmico, há diferentes casos de capaz com leitura epistêmica pura e esses casos também ocupariam posições distintas na estrutura, conforme seu grau de gramaticalização:

\footnotetext{
${ }^{29}$ Para uma análise de capaz como marcador negativo enfático, remetemos o leitor a Cavalcante e Simioni (2019).

${ }^{30}$ Conforme o original: “como negación enfática, es decir, para rechazar una posibilidad planteada, con un valor similar al de 'absolutamente imposible"”.
} 
(54) Construções de capaz com sentido epistêmico

(i) construções do português brasileiro e do espanhol [(é / es) capaz [de DP VINF]], em que a cópula pode ser omitida e um sujeito, pleno ou não, é realizado no domínio infinitivo;

(ii) construções do português brasileiro e do espanhol [(é / es) capaz [que oração]], em que capaz vem acompanhado de complemento finito no subjuntivo e a cópula pode ser omitida;

(iii) construções do espanhol e do português [capaz [que oração]], em que a cópula não está presente e capaz vem acompanhado de complemento finito no indicativo (construções- $C$, cf. denominação de Cruschina e Remberger (2018));

(iv) construção do espanhol [capaz [oração / constituinte nominal]], em que capaz funciona como um advérbio de dúvida com alcance sobre uma oração ou sobre um nominal.

Não é nosso objetivo discutir em detalhes as estruturas sintáticas dessas construções. Apontamos apenas que as construções em (i) e em (ii) são bioracionais, ao passo que as construções em (iii) e em (iv) são mono-oracionais, deixando para estudos futuros a determinação dos pormenores das estruturas sintáticas. ${ }^{31}$

Com relação ao uso de capaz que denominamos discursivo, argumentamos que ele realiza mais um estágio no percurso de gramaticalização de capaz, tornando-se um marcador pragmático. Capaz discursivo ocuparia assim uma posição mais alta do que capaz epistêmico na estrutura oracional. ${ }^{32}$ Essa posição seria uma projeção acima de $\mathrm{CP}$, uma projeção dedicada às relações pragmáticas / discursivas e ligada ao ponto de vista do falante. ${ }^{33}$

\section{CONSIDERAÇÕES FINAIS}

Neste artigo, apresentamos uma descrição detalhada dos usos da expressão capaz em português brasileiro e em espanhol. Nossa hipótese é que os diferentes usos dessa expressão representam estágios de gramaticalização distintos. A partir dos parâmetros propostos por Heine e Narrog (2012) para caracterizar o processo de gramaticalização, mostramos que capaz adjetivo, que funciona como um modal habilitativo nas duas

\footnotetext{
${ }^{31}$ Salientamos que Cruschina e Remberger (2018) propõem que, no caso das construções-C, capaz deve ocupar uma posição acima de ForceP, em um domínio ligado ao ponto de vista do falante. Os autores adotam as propostas de Speas e Tenny (2003) e Hill (2007) com relação a esse domínio.

${ }^{32}$ Rodrigues e Lunguinho (2019) propõem que capaz ocuparia uma posição na projeção Speech Act (SAP), acima de ForceP, adotando a proposta de Hill (2014) para essa projeção. Deixamos para estudos futuros uma comparação entre essa análise proposta para capaz discursivo e a análise de Cruschina e Remberger (2018) proposta para as construções- $C$. Cruschina e Remberger afirmam que capaz que do espanhol e capace che do italiano teriam uma conotação epistêmica objetiva, ao passo que as outras ocorrências das construções- $C$ abordadas teriam uma conotação epistêmica subjetiva. Os autores não aprofundam, no entanto, a discussão sobre capaz que / capace che. É possível supor que às construções-C com conotação objetiva possa ser atribuída uma análise distinta da análise discutida no artigo.

${ }^{33}$ Um parecerista aponta que, uma vez que capaz discursivo se encontra em uma posição periférica na estrutura oracional, associado a uma projeção responsável por codificar relações pragmáticas / discursivas e relacionada ao ponto de vista do falante, seria importante verificar como se dá a interação entre esse tipo de capaz e categorias que se alojam na periferia esquerda e dotadas de forte importe pragmático / discursivo, como tópicos, advérbios modais e discursivos, vocativos, marcadores discursivos e interjeições. Apresentamos uma breve interação do capaz discursivo com o vocativo cara, em Rodrigues e Lunguinho (2019). Ampliando a base de dados de modo a incluir as categorias apresentadas, certamente teremos pistas robustas para refinarmos a proposta sintática apresentada para capaz discursivo. Esse trabalho encontra-se na agenda de pesquisas futuras.
} 
línguas, tem seu contexto de usos estendido, perdendo seu sentido original de capacidade / habilidade e adquirindo um sentido associado à modalidade epistêmica. Argumentamos igualmente que o que chamamos de capaz epistêmico corresponde, na verdade, a diversos estágios de gramaticalização, iniciando-se por um estágio em que capaz tem um sentido que Castroviejo e Oltra-Massuet (2018) denominaram de acidental. Esses estágios são caracterizados principalmente por estarem relacionados a dois tipos de estrutura: nos estágios iniciais, a estrutura da sentença seria bi-oracional e, nos estágios finais, monooracional. A expressão capaz com leitura epistêmica em português brasileiro e em espanhol americano se encontram, aparentemente, em estágios distintos do processo de gramaticalização, tendo o espanhol americano concretizado esse processo, fazendo uso frequente da estrutura que Cruschina e Remberger (2018) denominaram de construções$C$. No entanto, o português brasileiro apresenta um uso discursivo de capaz que não é encontrado em espanhol com a mesma abrangência, uma vez que é restrito a certos dialetos. Esse uso discursivo precisa ser mais bem caracterizado para que se possa mostrar como as leituras de surpresa / incredulidade e negação são alcançadas. Certamente, temos, nesses casos, a passagem de uma leitura mais objetiva para uma leitura subjetiva.

\section{$\overline{\text { REFERÊNCIAS }}$}

ALEZA IZQUIERDO, M. Morfología y sintaxis. Observaciones gramaticales de interés en el español de América. In: ALEZA IZQUIERDO, M.; ENGUITA UTRILLA, J. M. (orgs.). La Lengua Española en América: normas y usos actuales. València: Universitat de València, 2010. p. 95-224.

BASSI, A.; GÖRSKI, E. M. A multifuncionalidade do item capaz na fala gaúcha: uma abordagem baseada no uso. Alfa, v. 58, n. 3, p. 593-622, 2014. DOI: https://doi.org/10.1590/1981-5794-1409-4.

BYBEE, J.; PERKINS, R.; PAGLIUCA, W. The Evolution of Grammar. Tense, aspect, and modality in the languages of the world. Chicago: University of Chicago Press, 1994.

CASTROVIEJO, E.; OLTRA-MASSUET, I. Generic and action-dependent abilities in Spanish 'Be capable'. Glossa: a journal of general linguistics, v. 3, n. 1, p. 1-32, 2018. DOI: https://doi.org/10.5334/gjgl.495.

CAVALCANTE, R.; SIMIONI, L. Capaz como marcador negativo enfático no dialeto gaúcho. Revista de Estudos da Linguagem, v. 27, n. 2, p. 669-700, 2019. DOI: https://doi.org/10.17851/22372083.27.2.669-700.

CRUSCHINA, S. The expression of evidentiality and epistemicity: Cases of grammaticalization in Italian and Sicilian. Probus, v. 27, n. 1, p. 1-31, 2015. DOI: https://doi.org/10.1515/probus-2013-0006.

CRUSCHINA, S.; REMBERGER, E.-M. Speaker-oriented syntax and root clause complementizers. Linguistic Variation, v. 18, n. 2, p. 336-358, 2018. DOI: https://doi.org/10.1075/lv.16009.cru.

DI TULLIO, Á.; KORNFELD, L. M. Marcas de modalidad epistémica en el registro coloquial. In: DI TULLIO, Á. (org.). El Español de la Argentina: estudios gramaticales. Buenos Aires: Eudeba, 2013. p. 83-103.

Diccionario Integral de Español de Argentina. Buenos Aires: Tinta Tresca, 2008.

GRANDÉZ ÁVILA, M. A Functional Approach to the Subjectification of Facultative Meaning: the case of capaz in American Spanish. Dissertação de Mestrado. Amsterdam: University of Amsterdam, 2010. Disponível em: http:// dare.uva.nl/cgi/arno/show.cgi?fid=184837.

HEINE, B.; NARROG, H. Grammaticalization and linguistics analysis. In: HEINE, B.; NARROG, H. (orgs.). The Oxford Handbook of Linguistic Analysis. Oxford: Oxford University Press, 2012. p. 401-423.

HERNANZ, M. L. El Infinitivo. In: BOSQUE, I.; DEMONTE, V. (orgs.). Gramática Descriptiva de la Lengua Española. Buenos Aires: Espasa Calpe, 1999. v. 2, p. 2196-2356.

HILL, V. Vocatives and the pragmatics-syntax interface. Lingua, v. 117, n. 2, p. 2077-2105, 2007.

HILL, V. Vocatives. How syntax meets with pragmatics. Leiden: Brill Publishers, 2014.

HOPPER, P. J.; TRAUGOTT, E. C. Grammaticalization. Cambridge: Cambridge University Press, 2003.

KENNY, A. Human abilities and dynamic modalities. In: MANNINEN, J.; TUOMELA, R. (orgs.). Essays on Explanation and Understanding. Dordrecht: Reidel, 1976. p. 209-232.

KOCHER, A. Claro que Son Adverbios: Analisis de un proceso de gramaticalizacion. Dissertação de Mestrado. Viena: University of Vienna, 2014. 
KOCHER, A. From verum to epistemic modality and evidentiality: On the emergence of the Spanish Adv + C construction. Journal of Historical Linguistics 7(1/2). 78-111, 2017. DOI: https://doi.org/10.1075/jhl.7.1-2.04koc.

KRATZER, A. The notional category of modality. In: EIKMEYER, H. J.; RIESER, H. (orgs.). Words, Worlds, and Contexts: New approaches in word semantics. Berlin: de Gruyter, 1981. p. 38-74.

KRATZER, A. Modality. In: VON STECHOW. A.; WUNDERLICH, D. (org.). Semantics: An international handbook of contemporary research. Berlin: de Gruyter, 1991. p. 639-650.

KRATZER, A. Modals and Conditionals. Oxford: Oxford University Press, 2012.

LEHMANN, C. Thoughts on Grammaticalization. Berlin: Language Science Press, 2015.

NEGRONI, M. M. G.; SPINOLA, S. S. Marqueurs de discours et distanciation: une étude contrastive de peut-être, capaz et por ahí. Estudios Románicos, v. 22, p. 53-64, 2013.

PALMER, F. R. Mood and Modality. 2a ed. Cambridge: Cambridge University Press, 2001.

PIMPÃO, T. S.; SANTOS, W. S. Variação estável ou mudança em progresso? A expressão do modo subjuntivo em três variedades do português brasileiro. Caderno Seminal Digital Especial, v. 30, n. 30, p. 248-290, 2018. DOI: https://doi.org/10.12957/cadsem.2018.33066

PORTNER, P. Modality. Oxford: Oxford University Press, 2009.

REAL ACADEMIA ESPAÑOLA / ASOCIACIÓN DE ACADEMIAS DE LA LENGUA ESPAÑOLA. Nueva Gramática de la Lengua Española - NGLE. Madrid, Espasa-Calpe, 2009.

REAL ACADEMIA ESPAÑOLA. Banco de dados (CREA). Corpus de Referencia del Español Actual. Disponível em: 〈http://www.rae.es>. Acesso em: agosto 2020.

REAL ACADEMIA ESPAÑOLA. Banco de dados (CREA). Diccionario Panhispánico de Dudas. Disponível em: < https://www.rae.es/dpd/capaz>. Acesso em: outubro 2020.

ROBERTS, I. Diachronic Syntax. Oxford: Oxford University Press, 2007.

ROBERTS, I. Syntactic Change. In: CARNIE, A.; SIDDIQI, D. \& SATO, Y. (orgs.). Routledge Handbook of Syntax. London: Routledge, 2014. pp. 391-408.

ROBERTS, I.; ROUSSOU, A. Syntactic Change. A minimalist approach to grammaticalization. Cambridge: Cambridge University Press, $2003 . \quad$ DOI: https://doi.org/10.1017/CBO9780511486326.

RODRIGUES, P.; LUNGUINHO, M. V. A pragmaticalização de capaz em português brasileiro e a codificação da atitude do falante. Revista de Estudos da Linguagem, v. 27, n. 2, p. 549-574, 2019. DOI: $10.17851 / 2237-2083.27 .2 .549-574$.

RODRÍGUEZ ESPIÑEIRA, M. J. Cambio semántico y sintáctico en las construcciones de capaz. In: GARCÉS GÓMEZ, M. P. (org.). Perspectivas Metodológicas en la Elaboración de un Diccionario Histórico. Madrid / Frankfurt: Iberoamericana / Vervuert, 2018. p. 117-186. DOI: https://doi.org/10.31819/9783954879267-005.

SPEAS, M.; TENNY, C. Configurational properties of point of view roles. In: DI SCIULLO, A. M. (org.). Asymmetry in Grammar. Amsterdam: John Benjamins, 2003. p. 315-344. DOI: https://doi.org/10.1075/la.57.15spe.

TEIXEIRA, L. R.; GRITTI, L. L.; KOSLINSKI, E. Algumas considerações semântico-pragmáticas sobre capaz. Cadernos de Estudos Linguísticos, v. 61, p. 1-25, 2019. DOI: https://doi.org/10.20396/cel.v61i0.8654342.

VAN GELDEREN, E. Grammaticalization as Economy. Amsterdam: John Benjamins, 2004.

VON WRIGHT, G. H. An Essay in Modal Logic. Amsterdam: North Holland, 1951.

Recebido: $12 / 10 / 2020$

Aceito: $1 / 6 / 2021$

Publicado: $15 / 7 / 2021$ 